plete immunity from recurrence after operation. The confounding of this form of disease with those tumours composed of real cancer, has caused the liability to error, and the variance of opinion of different surgeons in estimating the curability or the probability to recurrence of the disease after excision: removal of the first, viz., epithelioma of the tongue, lip, or penis, being followed by recovery, as the rule, whilst removal of true cancer is hardly ever more than a palliative measure; tolerably speedy recurrence taking place in nearly every case of the removal. For prevention of the recurrence of epithelioma, it is necessary that the growth be excised early, and that the knife be carried wide of the disease, so that all the deposits may be extirpated. If there be delay of the operation until after the disease has contaminated the absorbents, excision of the original mass does not effect a cure, part of the morbid structure being still left behind in these lymphatics, which will go on increasing in extent as if the primary mass still remained. If however, we excise at as early a stage of the disease as you saw me do in the cases of cancer of the lip and penis, there is no doubt that long life and perfect immunity may be insured. In cancer of the tongue, recurrence is more common than elsewhere, owing, I believe, to the difficulty and danger of thoroughly removing the disease, when infiltrating the lingual substance widely and deeply. Of the rarity of recurrence, the best proof is, that comparatively seldom do patients with "cancer" of the lip or penis return to us with a fresh growth, and when they do it is mostly a deposit in the neighbouring lymphatic glands, which had probably been contaminated before the operation, and not in the cicatrix itself, nor in internal organs. I have myself operated, eight, ten, and twelve years ago, on patients who have enjoyed good health to the present time, bearing nothing more than the seam left where the lip had been notched. I also know of a case of amputation of the penis where the patient has lived nearly thirty years after the operation; and during the last ten years I have removed the penis, in several cases of epithelioma, from men now doing well, and free from any return. In fact, epithelioma is, in its origin, but a local disease, arising from some special irritation, as in "chimney-sweeps' cancer," from the irritation of the soot; in " cancer of the tongue," from a ragged tooth; in "cancer of the penis," from a tight pressure retaining the secretions of the glands. In fact, the progress of epithelioma closely resembles that of a syphilitic sore. Just as the syphilitic virus produces its ulcer before any constitutional effect results, which does so-first by contamination of the lymphatics, and, after a longer interval, by the poisoning of the blood, and then the induction of general cachexy; so, in epithelioma, a precisely similar series of symptoms accompany the progress of the disease that has been primarily established by the local irritation. In epithelioma, as in syphilis, you have a sore resulting from local irritation, you have no sign of constitutional disturbance or cachexy for some months, or even longer, until the glands take up the poison, the blood then becomes contaminated, and marked cachexy sets in.

With regard to the mode of removal of epitheliomatous growths, I strongly advocate the knife. By the knife they can be removed much more cleanly, safely, expeditiously, and with less suffering, than by caustic. Should, however, caustic be deemed preferable in any case, the most powerful should be applied, so that the whole mass may be immediately and thoroughly destroyed, that the effect may be the same as when the knife is used. But if the less active caustics be employed, as the nitrate of silver, for instance, the cauterising effect is too weak for the destruction of the parts, and an irritating effect is produced, in addition to the caustic one; the neighbouring tissues become inflamed and infiltrated by plastic matter, which state of inflammation and infiltration is highly favourable to the spread of epithelial deposit.

Chicony and Beiladonna. An apothecary of Passy, named Cadet, was lately tried by the Tribunal of Correctional Police for gross imprudence. The offence, which was clearly proved, consisted of his having sold for a sick person, chicory, in which by some means a small quantity of belladonna had got mixed; and so the patient was seized with vomitings and other symptoms of poisoning. The man said that he had sold the chicory as he had received it, and that he could not be expected to examine minutely every small portion that he disposed of to see that no strange substance had got mixed with it; but the Tribunal ruled that he was bound to do so. In addition, it was shown that the man had been insolent to the commissary of police who went to his shop on the matter. He was condemned to a fortnight's imprisonment.

\section{yacation a dectures}

\section{FIBRINOUS DEPOSITION IN THE HEART:}

ITS HISTORY AND PRACTICAL MEANING.

DELIVERED AT THE GROSVENOR PLACE SCHOOL OF MEDICINE.

By BENJAMIN W. RICHARDSON, M.A., M.D., M.R.C.P. Lecturer on Physiology at the School, and Senior Physician to the Royal Infirmary for Diseases of the Chest.

LECTCRE III.

Symptoms of Fibrinous Concretion (continued). Pathological Changes incident to Fibrinous Deposition in the Heart.

$$
\text { [Concluded from p. 184.] }
$$

Examples in which there is a relative increase of fibrine, leading to deposition, are of different kinds. As I have already explained, the increase may relate to deficiency of water or menstruum, or to deficiency or over-distribution of the alkaline solvent of the fibrine. These cases divide themselves naturally, therefore, into two classes.

Cases of the first class are met with most strikingly in cholera. In fatal cholera, if the symptoms are much prolonged and the blood is drained of its fluid to the last extreme, the blood is found after death, as might be expected, condensed to a treacly mass everywhere, with, as a general rule, a fibrinous separation in the heart, usually, in these instances, I believe, on the left side. The symptoms of concretion here are not clearly marked ; for those pertaining specially to the disease mask the specific signs of deposit. In phthisis attended with profuse colliquative discharge either from the skin or the alimentary mucous surface, the same tendency to deposition may develope itself. From this cause, patients sometimes die in consumption at an early stage, before there is set up any sufficient disorganisation to destroy life by the arrest of respiration, or by discharge from the lungs. A woman aged 44, two of whose sisters had died phthisical, was under my care in 1850. She had symptoms of tubercle at the apices of both lungs; but there was little cough, and actually no expectoration. Three months before her death, her life was threatened from profuse discharge from the bowels; but, under astringents, this flux was stopped, and no further bowel derangement followed. Soon afterwards, she was seized with violent heats, followed by the most profuse perspirations. The symptoms were almost of the ague type, and were amenable to no treatment. Mean. while, the disease of the lung remained latent; but the appetite failed, and the tissues melted. Suddenly she commenced to sink, and died with all the signs of obstruction on the right side of the heart. I found, after death, tubercular deposit at the apices of both lungs ; and a heart large, soft, and thinned. The right cavities of the organ were literally filled with separated fibrine, the concretion extending into the pulmonary artery; and in the left cavities there was also a deposit, which extended into the aorta. The concretions on both sides had firm hold upon the cardiac wall. The blood was coagulated in the vessels.

The examples in which the fibrine becomes deposited in the heart, from loss of its solvent, are very numerous. We may, indeed, in reference to these cases, lay down a general proposition to this effect-that whatever cause slowly enfeebles the circulation sufficiently, without producing a fluid condition of blood, leads to a deposit of fibrine. By virtue of this law, we may have a deposition of fibrine during a prolonged syncope, after injuries which have produced shock, and after the administration of some poisons which slowly paralyse the heart, such as. opium.

I am indebted to my friend and colleague, Dr. Cockle, for the history of a case in which concretion on the right side of the heart followed a severe injury. The case has a special value, from the circumstance that the mode of deposition was peculiar, as the sequel will show. A man was crushed by the fall upon him of brickwork. He was conveyed to the Royal Free Hospital, where it was found that there was fracture of the pelvis and thigh. The shock was extreme; but he lived on for four 
days, rallying a little, when he was suddenly seized with into. lerable dyspnces, followed by congestion of the lung, and death. At the post mortem examination, it was found that a band of concretion (Fig. 7), taking a firm hold on the right auricular

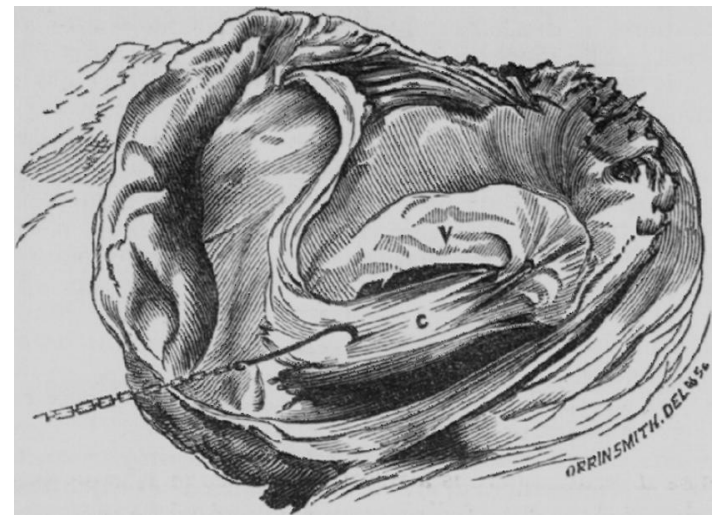

Fig. 7.-V. Portion of Tricuspid Valre. C. Conoretion.

wall, passed downwards into the ventricle, where, making a spiral turn around the tendinous cords of the tricuspid valve (Fig. 8), it looped up the curtains of the valves, and entirely

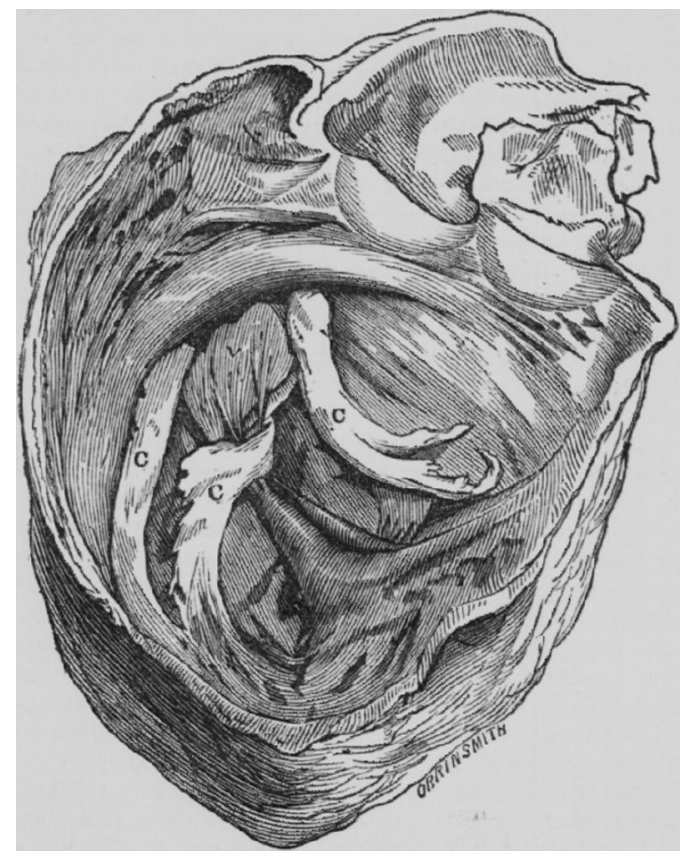

Fig. 8.-C C C. Concretions.

occluded the auriculo-ventricular opening. By the side of this central concretion lay two others beneath the curtains of the valves, and less adherent.

I should but waste time to deliver more examples of this class of cases. Whoever chooses to remember the simple fact that, whenever the circulation is slow and the blood charged with no new solvent, deposition is an imminent occurrence, will understand the signs of concretion whenever they occur, and their origin. If I have to add anything to this observation, it is this-that whatever condition exists favourable to fibrinous separation, such as anwmia, or its opposite where the blood is condensed, in such conditions very trivial depressing influences will turn the scale from imperfect solution of fibrine to abso. lute separation.

The mention of those conditions of system farourable to deposit from a change in the relative quantities of the blood constituents, leads me naturally to those examples in which there exists what I have designated as sponta. neous separation of fibrine. We have seen that this state, curiously enough, may exist in diseases approaching to those in which the blood is made permanently fluid. In some forms of low fever, for instance, we have at the earlier stages deposit, and thereupon the exhibition of symptoms which run through. out parallel with those of the typhoid itself. I select an excel. lent illustration of this form of disease from the Dublin Hos. pital Gazette for December 15th, 18t1. The report is by $\mathbf{M r}$. Rambant; the physician was Dr. Corrigan.

"Matthew Walsh, aged 70, was admitted into the Hardwicke Fever Hospital on November 20th, 1845, fourteen dajs ill. For the last one or two years, ho had been much exposed to cold, and suffered much from poverty. Fourteen days before admission, he was seized with rigors, headache, and vomiting. He became, as he said, worse from day to day, lay in a small close room, and received but little attendance. The symptoms on admission were, shivering and cold extremities; the pulse very weak; the tongue dry, hard, and dark brown; all the secretions and excretions were scanty; the intelligence imperfect. He rested on his back, and made no complaint. The treatment was ether, ammonia, and brandy. On the 21st, 22nd, and 23rd, his sinking continued. He lay in bed on his back, still complaintless, with a pulse hardly perceptible. There was no tymparitis of the abdomen. On tho 23rd, the tongue was moist, with slight mucous rattlo in the throat. On the 21th, he showed more restlessness, with an inclination to attempt getting out of bed; on which day he died.

"At the post mortem examination, the lungs were found healthy in texture, with some effusion (not considerable in quantity) into the bronchi from the lungs, but moderately collapsed. The tissue of the heart was healthy. The left ven. tricle contained grumous dark coloured blood. On slitting up the right ventricle, the pulmonary artery, and its branches, a singular appearance was presented. A bulbous shaped polypus (concretion) lay in the right ventricle, but was not sufficieut to fill it. This polypus, narrowing gradually as it passed into the pulmonary artery, extended along this vessel, being of about the thickness of a quill; then it divided at the bifureation of the pulmonary artery, and continued its ramifications along the arterial branches. This extensive polypus of fibrine was so firm that, taking it by the root which lay in the right ventricle, it was drawn out, with all its attached branches, unbroken from the pulmonary artery. It was not attached anywhere to the sides of the urteries, but lay like a cord along their centre."

The following observations by Dr. Corrigan, in relation to this case, are, like all observations that have proceeded from his clear and unprejudiced mind, of great practical value.

"Two questions naturally suggest themselves here. 1. Was this polypus only formed in the last dying moments? 2. Had it any effect as a cause of death? As to the first question, I think the structure of the polypus itself shows that it must have been a considerable time in the process of formation, pro. bably for some days. It was very nearly destitute of the colouring matter of the blood, except in the smaller ramifications of it. It was not of great size, such as we generally see in polypi of recent formation in the cavities of the heart, but was firm, comparatively hard, and small compared with the size of the cavities in which it lay. But the most satisfactory proof, probably, of its formation having occupied some time, is to be found in its structure. It consisted of distinct separate layers of fibrine. The outer layer or layers were comparatively soft, and, when laid hold of and pulled on, could be most readily drawn down off the midale fibrinous cord, which constituted the middle of this long.branched, tree-like polypus. This centre fibrinous cord was very firm and pale coloured. Those separate layers into which the polypus casily separated, resembled exactly the separate layers of lymph which are found in successive deposits of lymph in the trachea, in croup. On carefully examining this construction of the polypus, its position in the centre of the vessels, its extent in length, and its small diameter as compared with the size of the ventricle and vessels, it seems quite evident that this singular formation has been tho growth of probably some days, and has been either the causo or the consequence of the sinking process of the circulation. But whether the cause or the consequence, it is plain that once formed, even in small extent, it would prove a serious hindrance to the circulation, and would most probably, even necessarily, cause death by its constantly increasing size and proportionately increasing obstruction to the function of the lungs and to the circulation."

Conditions of blood favourable to deposition may occur also in scurvy, and in purpura. I have already stated briefly the history of a case of this latter lind occurring in a child. The body of this child, during life, was covered with purpuric blotches, and such was the tendency to effusion, that even firm pressure on a clear spot of skin would give rise to a temporary blotch. Ono would hardly have 
conceired such ondition favourable to fibrinons deposit; but, after some weeks of great anxiety and languor, death occurred suddenly. And in the beart, in the right auricle, a concretion of fibrine tilled the cavity, and sent a long prolonga tion into the inferior cava. The concretion was laminated, was clearly formed before death, and was the immediate cause of death.

As I have said once before, there may be deposition of fibrine in the heart as the resuit of paralysis of the circulatory organs by the action of poisons which depress, witbout adding to the circulating fluid any solvent of fibrine. There is much room for investigation in relation to this subject. In an animal struck down by the respiration of sulphuretted hydrogen, and left afterwards for some hours in pure air, there may be fibrinous separation. In a dog killed by a large dose of morphia, the death being prolonged over twenty hours, I once found also such separation, the concretion being on the right side, and filling the cavity, but being soft, and only slightly adherent. In the humun subject, I have had no personal experience as to the production of concretion from the absorption of poisons; but the following case, reported in the Lancet for 1837.8 , vol. ii, p. 626, by Dr. Frederick Page of Bescles (now of Landport), is of extreme interest, as indicating the possibility of deposition after the administration of arsenic. It may be a question truly whether, in this case, the deposit, which was clearly the immediate cause of death, was the result of the arsenic or of preexistent disease, independent of the arsenical dose; but, whether or not, the narrative deserves quotation in full.

"A fine healthy boy, aged $3 \frac{1}{2}$ years, swallowed a small piece of bread which was covered with butter, sugar, and arsenious acid (about eight grains), which his mother had just prepared to poison vermin. It appears she had just turned her back to him for a moment, during which time the child ate it. I was immediately sumuoned to attend, and exhibited an emetic of sulphate of zinc, which produced powerful romiting; and, in about twenty minutes from the time at which the poison was taken, the stomach appeared to be quite free from the drug. During the following three days, the child appeared to be as well as usual; but, on the morning of the fourth, be was attacked with slight difficulty of breathing, quick pulse, hot skin, loss of appetite, and anxious expression of countenance, without sickness, purging, or any indication of pain. In the evening, be was evidently sinking, and died on the following morning, at about five o'clock, continuing perfectly sensible up to the time of his death.

"On viewing the body, ten hours after death, some few dark spots were visible on the surface. Nothing particular offered itself to notice on examiniug the stomach and the organs of digestion, with the exception of one or two slight traces of in. flammation in the former viscus; the liver was enlarged, hardened, and of a pale yellow colour; the bladder was full, distended; the lungs and cavities of the pleura were healthy; the pericardium was filled with a pale straw-coloured transparent fluid. On dividing the venæ cavæ close to the auricle, a considerable lump of semitransparent, perfectly organised, coagulable lymph, fell from this cavity, in which was dis covered much more. On opening the ventricles, large strings of the same substance were found to occupy their cavities, interwoven with the carnex columnæ, and extending from the left into the aorta, nearly filling up the ventriculo. aortic opening. The walls of the heart were pale, flabby, and soft."

It is probable that, in some forms of poisoning by the mineral acids or by inhalation of chlorine, where life is prolonged for some hours, separation of fibrine might also occur. But these probabilities we must wait to see solved.

Symptoms of Concretions of a Chronic and Anomalous kind. Before learing the subject of symptoms, I must not forget to mention certain ones of an anomalous character, and sometimes prolonged over a considerable period.

It may happen that, in the course of an acute form of symp. toms of concretion, relief may occur suddenly to the labouring heart, with the appearance of obstruction in a remote part of the circulation. It is worth while to recall the fact that Dr. Chisholm, in giving the history of his cases in Granada, speaks of the symptoms showing a tendency to terminate in what, using the language of his time, he calls a "metastasis". One patient was relieved all at once, and without any evident cause; but perceived at the same instant an excruciating pain little below the ellow, and nearly about the middle of the thigh. He continued free of the symptoms of polypus, but suffered from large abscesses at the points of the extremities where the pain was dereloped. Through the kindneas of $\mathrm{my}$ friend Dr. Sibson, I was once enabled to see a case very similar to the one just noted. A man came under Dr. Sibson's care, sufering from terrible embarrassment of the heart. The em. barrassment continued for many days, when suddenly it was removed, but was followed at the same instant by numbness and coldness of the left arm, which continued for a week after the event. The man had valvular disease of the heart; but, after this sudden relief, the anxiety about the heart did not return.

These cases are rare; bnt, as they ocour, I must describe them, and their nature. The peculiar modification of symptoms is easily read off. It is due to the sudden dislodgment of a concretion from, the left side of the beart with the arterial stream. The symptoms of major obstruction are removed, and new symptoms of minor obstruction are set up. The minor symptoms are recnverable without necessary loss of life or even of limb; for a limb will not die when there is free anastomosis.

There is a second class of cases in which conoretion is produced in the heart, and does not at once destroy life, but gives rise occasionally to symptoms of the most distressing character, and which, often renewed, are at last fatal. These symptoms are so peculiar in different cases, that it would be difficult to subject them to any given descriptive rule. I shall prefer to illustrate what $I$ know of them from histories of clinical facts. The following case was reported to me by Dr. Sayer.

A widow lady, aged 40 , who had borne four children, had been the subject of much grief and anxiety; the extravagant and intemperate conduct of her late husband (who died in 1819) having reduced her from a state of affluence to the verge of indigence. She had suffered for several years from uneasiness about the chest, accompanied with deep and frequent sighing. In March 1825, there was increased nneasiness about the chest, a sense of oppressive weight, frequent deep and prolonged inspirations, a weak, slow, tremulous and unequal pulse, a loaded condition of the superficial veins, muddy hue of skin, an cdematous state of the feet and ankles, and withal a tendency to somnolency.

At the end of June, she had improred so much, that she was able to leave town by coach, and to repair to the sea-side, whence she returned home, early in August. She was now in that degree of health, to which she had been habituated for the last few years-being able to attond to her household duties, and to the education of her younger children.

At the end of September, she became suddenly afflicted with a return of all the former symptoms; for which little or no relief could be afforded. Sho died on October 30 th, presenting during the last week of life symptoms of hydrothorax, hydrops pericardii, and codema of the lower extremities, extending from the feet to the upper part of the thigh.

At the autopsy, 21 hours after death, the brain was found perfectly healthy. Extensive serous effusion existed in both pleural cavities. The lungs, quite free from adhesions, were engorged with dark blood. The pericardium contained a small quantity of effused fluid. The heart seemed considerably en. larged, and was surrounded at its base by a large quantity of fat. A circular ulcerated spot, covered with a thin layer of purulent matter, and measuring an inch and one-eighth of an inch in diameter, was discovered on the upper surface of the heart immediately beneath the junction of the right auricle and ventricle. Both the cardiac carities on the right side were thicker and firmer than natural. The cavity of the auricle was cnlarged in size, and the musculi pectinati were unusually developed. Within the auricula of this auricle there existed an abnormal formation, a flbrinous concretion, firmly attached to the muscular wall. When pulled with considerable force, it broke off close to the place of attachment, leaving the base behind firmly adherent. The concretion measured two inches in length, and an inch in breadth at the base. It weighed three drachms and five grains (troy weight), and tapered to half an inch in diameter at its extremity, from the anterior edge of which issued an appendix, which measured an inch and a half in length, and terminated abruptly. The walls of the right ventricle were slightly thickened, and the columnæ carneæ, chordæ tendineæ, and tricuspid valves, were increased in size and firmness. In this ventricle, and amongst the columnæ carnex, near the septum ventriculorum, there was found another similar abnormal formation, extending into the pulmonary artery and over the semilunar valres. The concretion measured eight inches in length, the last two being thread-like or filamentous. The width at the base was an inch. When pulled with much force, it broke off like the 
one in the auricle close to the point of adhesion, leaving the base firmly attached. It weighed two drachms and thirty. seven grains (troy). The pulmonary artery and semilunar valves were natural, and so also were the pulmonary veins. The foramen ovale was perfectly closed, but its margin was more distinct than usual. The left auricle was in its normal condition; the left ventricle was thicker in substance than is normal ; and the mitral valves, the chordæ tendineæ, and columnæ carneæ, had acquired a corresponding development: this cavity also contained a small free coagulum, in which the sepuration of fibrine had commenced. The arch of the aorta and the semilunar valves were healthy and sound. The heart weighed one pound, seven ounces, seven drachms, and fortytwo grains (troy weight). The abdominal viscera were all normal. The venous system generally was loaded with dark blood.

In the succeeding case, kindly forwarded to me by $\mathrm{Mr}$. Duncan R. McNab of Epping, the symptoms are peculiarly interesting, in that one modification of them-viz., an alleviation dependent on change of position of the body-proved the existence of concretion in a way singularly convincing.

"A labouring man," so Mr. McNab writes to me, "under our care was suddenly seized in the night with a sense of suffocation. After struggling awhile for breath, he partially recovered, and lived on for weeks, but breathing with great diffi culty. The only relief he could obtain was by placing himself in one position; viz., by lying with his face downwards, and resting on his elbows. This circumstance was so peculiar to me, that I was induced by it to examine the body after death. I found the lungs milk-white and bloodless. In the right ventricle of the heart was a white tape-like concretion, attached by its base to the anterior wall of the ventricle, and continuing upwards into the pulmonary artery.

"The position of this concretion explains the cause of the relief obtained by the act of lying with the face downwards. For when the patient was reclining on his back, the concretion must have floated across the pulmonary artery, and have checked the current; but when be lay on his face, the concretion would lie flat against the anterior wall, and the passage for the blood would be comparatively easy. I should add, that this man had consulted us about strange sensations in his heart a year or two previously; but his complaints were then regarded by us as due to profuse smoking, and as hypochondriacal in character."

Once more, there are cases where a fibrinous deposit, without causing rapid death, produces much the same class of signs as valvular disease; viz., lividity of the body and cedema. With the existence of this class of cases, and of the cause producing them, the illustrious Morgagni seems to have been well conversant, as the following history by him indicates:-

"A woman, previous to her death, had shown symptoms of universal tumidity of the body, and that livid hue which the skin usually exhibits when a great number of the subjacent veins are turgid with blood. The respiratory movements were performed with difficulty, and the pulse was feeble. The body of this woman was opened by Joseph Stancari, who found the vena cava and emulgent veins dilated, their coats partly cartilaginous, partly bony, and they, as well as the iliac and other veins, nearly filled with a hard polypous concretion."

Another case somewhat analogous to this has been given by Dr. Burrows, in his admirable Croonian Lectures (Medical Gazette, August 15, 1835) :-“A weak, emaciated, waxy-looking girl, who was under the care of Dr. Bright, suffered from palpitations of the heart. These were followed by œedema of the legs, great pain in them, and extreme enlargement of the superficial veins. In this state she died; the œdema gradually going off, and becoming succeeded by wasting. After death a yellow, laminated coagulum was found to fill the inferior vena cava and the iliac veins, thus fully accounting for the impeded circulation."

But the most remarkable example of this kind is one re ported by Dr. Fuller, in the London Medical Gazette for the year $18 \pm \pi$. I must refer the reader to Dr. Fuller's excellent report and observations for the full particulars of the case. Its leading points are these:-A thin and pallid woman was admitted into St. George's Hospital on June 11th, 1846, under the care of Dr. Page. She was suffering from extreme pain in the right foot and leg, and was passing albuminous urine, but had few constitutional symptoms. On the 22nd, an aggravation of her symptoms took place. The right foot became colder than the left, and assumed a mottled appearance, as if from incipient gangrene; the pain also became more severe, and febrile disturbance showed itseif. On the 27 th the whole of the right foot was perfectly black, and the leg greatly dis coloured up to the knee. On the 28 th a patch, of the most vivid red colour, presented itself on the hitherto black foot; and by the 30th almost all the toes on this foot, and the greater part of the foot itself, were of a brilliant scarlet colour, nevertheless, the whole foot remained perfectly cold. The femoral artery could be felt pulsating as usual; but it was hard and tense to the touch, and its contractions were evidently imperfect, as if from the blocking up of the cylinder. The left foot now became painful and gangrenous, while the peculiar redness already alluded to continued to extend up the right foot and leg, until it displaced the blackness, and continued some distance above the knee. On the 5th of July, vesications appeared on the right leg, and the left, which had gone through the same series of changes as the right, was becoming of the same bright red colour. Her back also showed a disposition to slough, and the extremities, from the hips downwards, had become perfectly cold. She continued to get worse until the 12th of July, when she refused food, and, after lying in a comatose condition (from which she could be roused, and was then quite sensible), she sank on the 15th, without any alteration in her symptoms. During the last week of her life, some parts of the legs and feet, which had presented the vivid scarlet appearance, became perfectly black, and emitted an in sufferable stench. The autopsy disclosed no peculiar lesion of the lungs, or of the structure of the heart; but the right cavities of the heart contained coagula of a mixed character, some dark, others fibrinous and recently coagulated, and one small one in the auricle, evidently of long standing -it was quite firm, for the greater part discoloured, and, when laic open, its centre was soft and cream-like. In the left ventricle was a coagulum presenting the same characters as the one last described ; but it was much larger, and occupied a considerable portion of this cavity, being entangled ard firmly fixed in the muscles of the fleshy columns, with which it appeared in some places to be connected by slender adhesions. The liver was healthy; the spleen congested, but otherwise healthy. The intestinal canal and organs of generation presented nothing remarkable. The right kidney, much reduced in size, presented a well-marked specimen of granular degeneration. Its artery and veins were healthy. The vessels of the left kidney were blocked up by firm coagula. The kidney itself, much increased in size, presented a singular appearance; both its structures were for the greater part filled with an extensive deposit of variegated appearance. The abdominal aorta, immediately after the giving off of the superior mesenteric, and the common internal and external iliac arteries, were all blocked up by firm, light-coloured coagula of long standing, and adhering slightly to the internal coat of these vessels. In some places, the centre of these coagula was softened and cream.like. The internal coat of the arteries was neither thickened nor discoloured. The vena cava inferior, at the entrance of the iliac veins, was also blocked up by similar coagula, which were traced downwards into the various larger branches of these veins; but the upper part of the cava was quite free from coagula.

Ihe muscles of the inferior extremities were discoloured all the larger arterial trunks which were examined were blocked up by coagula, similar to those observed in the iliacs. The arteries were traced down to the dorsum of the foot; the veins were also blocked up by similar coagula. No disease appearance could be detected about the coats of any of these vessels. The blood, examined microscopically, showed no unusual appearance.

There are, again, examples in which fibrinous concretions are formed in the heart, exist there for a time, and, without exciting any chronic or paroxysmal symptoms, destroy life at last by a sudden syncope. The old writers were so well conversant with this occurrence, that one of them, Queye, referred specially to it in an essay on syncope (Queye, "De Syncope et causis eam producentibus", Haller, Disp. Anat., vol. vii, Göttingen, 1735); and Cullen favoured the subject with a similar mention. In modern times, we have had clinical histories bearing in the same direction. In cases of the kind in question, the fatal result is usually preceded by some muscular exertion. I will give two examples.

In Guy's Hospital Reports, vol. iv, p. 157, Dr. Hughes has given a good illustration of this kind. The patient was a boy eleven years old, under the care of Mr. Aston Key. He died on passing a motion from the bowels. An old fibrinous clot, of the size of a pigeon's egg, blocked up three-fourths of the right auriculo-ventricular opening.

The case of the old lady, whose death was noticed in the first 
section of these lectures, and in whom an organised concretion existed in the left heart, is the second case of this lind to which I would refer. This lady had suffered certainly from symptoms which had been referred to the heart, but not of an intensity sufficient, as it seemed, to endanger life. Suddenly, after some tritling exertion, she fell and died almost instantly, the globular concretion being carried by the blood.stream into the aorta, and occluding it as effectually as a tight ligature around the vessel.

Lastly, the deposit of fibrine in the heart, in cascs of old standing heart-disease, may give rise to peculiarities of symptom re flecting on those of simple cardiac disorder on the one hand, and on those of concretion on the other. In the instance of a girl who had suffered for some years with hypertrophy of the heart and mitral induration, an acute but slight rheumatic attack led to depositiou, and to the most extensive deposition I have perhaps over witnessed. In the course of this case, about four days before death, the mitral murmur disappeared altogether; the pulse at the same time becoming most irregular, and so quick that it was barely to be counted. Without any marked general indications of obstruction from clot, this patient, while sitting up in bed taking drink, exclaimed "Oh dear, how weak I am!" and died instantly from syncope.

Now, in this case, the disappearance of the mitral murmur was accountod for fully at the post mortem examination. It was found that the indurated mitral valve was held back by a fibrinous band; while the absence of the special signs of con. cretion was accounted for by the great size and dilatation of the left cavity. I was not at the time when this case occurred prepared to account during life for the disappearance of the murmur; but in another similar case, I feel that any such difficulty of diaguosis would be greatly removed. There remains yet much to be done in relation to fibrinous deposition in hearts previously and chronically diseased. I have at this moment no further data on the suivject; and with this observation I close the history of the symptoms of concretion.

Pathological Changes incident to Fibrinous Deposition in the IIcart. Whencrer there is deposition of fibrine in the heart, leading to symptoms of obstruction and death, there are produced in other parts certnin changes which, though not necessarily organic, are deserving of consideration.

The condition of the lungs first calls for attention. The lungs are always changed; but the change varies from two of the widest extremes-i.e., from the extreme of bloodlessness to the extreme of congestion. These distinctions depend upon the position and size of the obstructing body. When the con. cretion is on the right side, and is of such size and in such position as to check the circulation to the lungs effectually, the state of the lungs is then very uniformly the same. The organs are inflated, blanched almost to pure whiteness, and bloodless. In some instances, to these signs emphysema is added: then the pleural membrane is seen elevated in bead-like rows over a considerable tract of the external surface. In children dying of acute hyperinosis, this emphysematous condition is, accord. ing to my experience, always present, and, as a general rule, present in the most marked degree. If the concretion, still supposing it to be on the right side, be so small or so placed that it will allow a current of blood to pass to the lungs, the normal force of the current being nevertheless considerably re. duced, then the lungs, instead of being blauched, are con. gested throughout, and even coudensed in depending parts.

When the deposition is on the left side of the heart, whether it obstruct much or little, and whether death be sudden or prolonged, the lungs are always congested. But, in prolonged cases, there is often more than congestion; there is effusion, codema, sometimes exudation of blood itself, profuse secretion into the bronchial passages, and condensation of structure in depending parts amounting to hepatisation.

The pleural cavities, in all forms of deposition, sometimes contain serum of a pale straw colour, which varies in amount, but does not extend to a sufficient amount to cause compression of the lung-structure. In one example, I observed that serum exuded into the pleural cavity coagulated on exposure to the air, a little fibrine having been thrown out with the serous fluid.

The pericardium usually contains serum in excess; but, again, not in sufticient excess to stop by its pressure the action of the heart. When this tluid is cleared away, one is often struck, especially in examining the bodies of children who have died of concretion laid down in the right auricle, with the peca. liar appeurance of the heurt: the auricle, from distension, is as large, or is even of larger size than the ventricle; the veins of the heart superficially are distended almost to rupture; and the whole appearance of the organ indicates the intensest con. gestion.

The condition of the large veins, and of the parts below the heart, the liver, kidneys, and spleen, in cases where the oen. cretion is on the right side of the heart, is one also of extreme congestion. In chronic cases, such as those related in a previous page, where the obstruction extends over weeks or months, there may be cedema of the lower parts of the body, or even effusion of fluid into the peritoneum. In a case seen by Mr. McNab, in which a child died with the signs of concretion on the right side, and in which the post mortem examination showed 8 firm concretion in the right auricle, with pathological appearances in the lungs such as have been so often mentioned -viz., bloodlessness and whiteness of texture-there was found intussusception in five portions of the small intestine, in one portion to the extent of three inches. Mr. McNab suggests that this intussusception may have been due to spasm arising from the deficiency of arterial blood in the intestine-a very probable hypothesis. The symptoms of concretion in this infant were observed first on Monday; its mouth then felt cold to the nipple of its mother; and it continued cold and apparently insensible to everything till Wednesday, when death oc curred. I have not in my dissections met with any such condition as is here described in cases of death from fibrinous deposition.

The concretion being on the left side of the heart, the congestion of the abdominal veins and organs is less determinate; for in fact the lungs receive a large supply of blood, and the congestion is shared by the two circulations, pulmonary and systemic. In very prolonged cases, nevertheless, the ocdema and other indications of central obstruction may have an extensive manifestation in the parts below the beart.

The brain is always congested when there is concretion on the right side, and this congestion may extend to effusion beneath the arachnoid or into the ventricles; but again the fluid effused is always small in quantity. Not unfrequently the sinuses of the brain will be found containing separate tubular deposits of fibrine. When the concretion is on the left side, the brain is also congested, as a general rule, but to a less extent.

It must always be a matter of care, in summing up the pathological appearances incident to concretion, not to confound these with conditions pertaining to other coincident forms of disease, nor to mistake secondary for the primary causes of the changes of structure which are presented by the scalpel. In the brief history I have given, I have kept this caution in view, and have intentionally reduced the description to the narrowest bounds, that there may be no chance of stepping beyond the simple and the true.

\section{oloriginal Communications. \\ EXPERIMENTAL WPICRISIS OF SOME LATE RESEARCHES ON LIVER-SUGAR.}

By J. L. W. Thudichus, M.D.

Tre discussion which has lately taken place at the Royal Society, of a paper by Dr. Harley, in which the views advanced some time ago by Dr. Pavy, and noticed at length in this JounNaI, relative to the glycogenic function of the liver, are controverted, recalls to my memory some experiments which I made in the early months of 1859 , with a view of testing the correctness of Dr. Pavy's chemical proceedings and physiological conclusions. The result of these experiments is adverse to the opinion of Dr. Pavy, and in accordance with that of Dr. Harley, and consequently confirmatory of the doctrine of the glycogenic function of the liver, as generally adinitted before the publication of Dr. Pavy's paper. My experiments have, moreover, afforded me an opportunity of ascertaining the sources of fallacy in at least two of Dr. Pavy's modes of pro. ceeding, and have tanght me the conditions under which oppo. site results may be obtained by the same experiment with the same proceeding - a fact which (as I am informed) was left unexplained by the late discussion.

A dog of fifteen pounds weight, which had for several days been fed upon tripe exclusively, was narcotised with puff-ball, and deprived of a small piece of his liver. This, without loss of time, was pounded with an equal amount of caustic potassa, without the addition of water; and the pale reddish magma was filtered through asbestos. The first filtrate, brought into 